\title{
Fuzzy Logic Enhanced Direct Torque Control with Space Vector Modulation
}

\author{
Jian-Ding Tan ${ }^{1}$, Siaw-Paw Koh ${ }^{2}$, Sieh-Kiong Tiong ${ }^{3}$, Kharudin Ali $^{4}$, Ahmed Abdalla ${ }^{5}$ \\ 1, 2,3 Institute of Sustainable Energy, Universiti Tenaga Nasional, Malaysia \\ ${ }^{4}$ Electrical, Electronic and Automation Enginnering Technology, TATI University College, Terengganu, Malaysia \\ ${ }^{5}$ Faculty of Electronic Information Engineering, Huaiyin Institute of Technology, P. R. China
}

\begin{tabular}{l} 
Article Info \\
\hline Article history: \\
Received Feb 1, 2018 \\
Revised Apr 20, 2018 \\
Accepted Apr 27, 2018 \\
\hline Keywords: \\
Direct torque control \\
Space vector modulation \\
Stator flux estimation \\
Fuzzy logic control \\
Induction motor
\end{tabular}

Article Info

Received Feb 1, 2018

Revised Apr 20, 2018

Keywords:

Direct torque control

Stator flux estimation

Induction motor

\begin{abstract}
Over the past few years, multiple types of modifications have been proposed onto the Direct Torque Control (DTC) scheme. Among others is the implementation of Space Vector Modulation (SVM). In this paper, two new control strategies are proposed onto an SVM-DTC. Instead of using PI torque and flux controllers, a fuzzy logic control method is implemented in the proposed modification to achieve a more constant switching frequency while minimizing the torque error. The fuzzy logic controller controls the voltages in direct and quadratic reference frame (Vd, Vq). This approach fully utilizes the switching capability of the inverter and thus improving the overall system performance. To overcome issues in open loop stator flux such as DC drift and saturation, a closed loop estimation method of stator flux is also proposed based on voltage model and low pass filter. The performance of the proposed control strategy is benchmarked with that of a conventional DTCSVM. Simulations and experiments were carried out and the results show that the proposed method outperforms the conventional DTC-SVM in terms of DC-offset elimination and overall system robustness.
\end{abstract}

Copyright (c) 2018 Institute of Advanced Engineering and Science. All rights reserved.

Corresponding Author:

Jian Ding Tan, Institute of Sustainable Energy, Universiti Tenaga Nasional, Malaysia

Email: tjianding@uniten.edu.my

\section{INTRODUCTION}

Direct Torque Control (DTC) is a control scheme that grants electronic variable speed motor controllers with an excellent torque manipulation [1]. With DTC schemes in the AC drives, the use of machine parameters can be minimized. However, despite the good performance that DTC has shown so far, there are still rooms for improvement is certain aspects of the scheme [2]. Over the past few years, scientists and researchers around the globe have been coming up with methods and modifications to improve DTC in terms of motor performance during start up, overload conditions, low speed spinning and many more [3]. Among other issues in a conventional DTC scheme is the high torque ripple generated [4]. Several methods to address this problem have been proposed in the literature, such as regulating the pulse duration of the output voltage vector so as to make it directly dependent on torque-ripple minimization. Although modifications as such can extensively reduce the torque ripple, the complexity of the overall algorithm is in praised and it becomes difficult to be implemented.

A standard DTC generally consists of a pair of hysteresis comparators, torque and flux calculators, a lookup table, and also a voltage-source inverter (VSI) [5]. Some major issues associated with this conventional setup can be found in the literature, including switching frequency that varies with operating conditions, high torque and flux ripples with current distortion, just to name a few. In the proposed fuzzy SVM-DTC strategy for induction machine reported in [6, 7, 8], two fuzzy logic regulators are adopted. These fuzzy regulators replaced classical PI regulators in the proposed scheme. Apart from this, another two 
different modifications were proposed in [8-12] to improve DTC performances. One of the proposed modification is to optimize the PI controller using Genetic Algorithm (GA). The other modification is carried out basing on a hybrid fuzzy sliding mode control theory. Some other researchers used a fuzzy PI controller in the speed control loop. This modification is carried out by substituting the PI controller to a hysteresis controller and replacing the switching table with SVM $[13,14]$. All the modified schemes showed significant improvements in relative to a conventional DTC. Beside fuzzy logic and GA, Artificial Neural Network (ANN) has also been proposed to enhance DTC. A multi layer neural network is implemented in [15] to emulate the traditional switching look up table method. This modification successfully obtained an optimal switching pattern for induction motors. In [15], a wavelet neural networks (WNN) is applied in a direct torque and flux control for the induction motor drives. The WNN controller with the structure of nonlinear auto regressive moving average based neural network (NARMA) is implemented as a speed controller to control the torque.

In this paper, two control strategies are proposed for DTC with SVM (DTC-SVM). The contribution of this paper is two-fold and can be summarized along the following lines. First, the PI torque and flux controllers are replaced with two respective fuzzy controllers. This enables the DTC-SVM scheme to minimize torque errors, reduce total harmonic distortions of stator current and provide a more consistent switching frequency. Secondly, a modified close loop integration algorithm of stator flux estimation is proposed. This algorithm scheme is carried out basing on a voltage model with the stator current in a low pass filter. Simulations and experiments were carried out to examine the performance of the proposed modifications. The results show that the proposed method is successful in minimizing torque errors. The ripples in the flux and the torque of the stator at low motor speed are significantly reduced.

\section{INDUCTION MOTOR MODELLING}

The modelling of an induction motor is expressed in a $\mathrm{d}-\mathrm{q}$ fixed reference frame in Equations (1) to (6)

$$
\begin{aligned}
& V_{s d q}=R_{s} i_{s d q}+\frac{d}{d t} \psi_{s d q}-j w_{g} \psi_{s d q} \\
& 0=R_{r} i_{r d q}+\frac{d}{d t} \psi_{r d q}-j\left(w_{g}-w_{r}\right) \psi_{r d q} \\
& \psi_{s d q}=l_{s} i_{s d q}+l_{m} i_{r d q} \\
& \psi_{r d q}=l_{r} i_{r d q}+l_{m} i_{s d q} \\
& T_{e}=\frac{3 p}{2} L_{m}\left(\psi_{s d} i_{s q}-\psi_{s q} i_{s d}\right) \\
& T_{e}-T_{l}=J \frac{d}{d t} w_{m}+B w_{m}
\end{aligned}
$$

Where $w_{g}, w_{r}$, and $w_{m}$ refer to generic reference system, rotor electrical and mechanical speed respectively. $R_{s}$ and $R_{r}$ denote resistances of stator and rotor. $L_{s}, L_{r}, L_{m}$ represent stator, rotor and mutual inductances. $\Psi_{\text {sdq }}$ and $\Psi_{r d q}$ stand for the stator and rotor flux in $d-q$ frame respectively. $T_{e}$ and $T_{l}$ are the torque of motor and load. $i_{s d q}$ and $i_{r d q}$ refer to currents of stator and rotor while $B$ and $J$ denote friction coefficient and inertia of the system. Figure 1 shows the equivalent circuit in d-reference frame and q-reference frame.

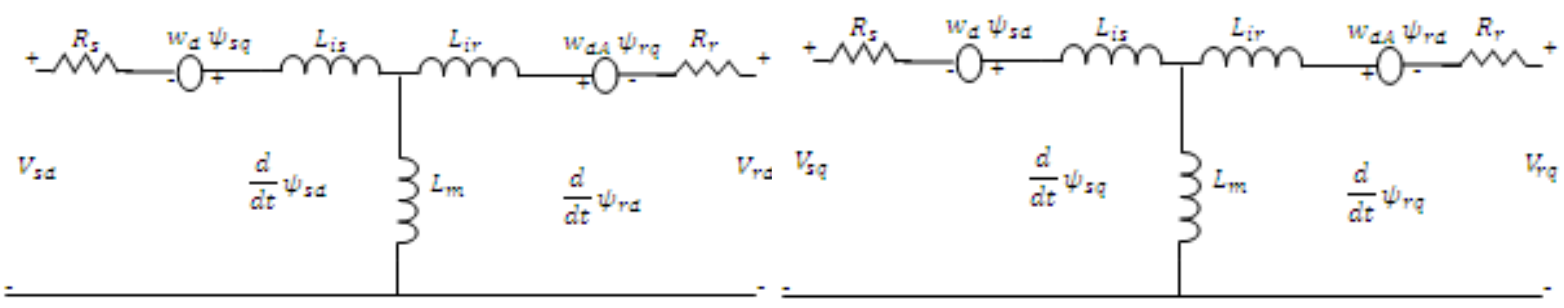

(a)

(b)

Figure 1. Equivalent circuits of induction motor in (a) d-reference frame (b) q-reference frame 


\section{DTC-SVM}

DTC is a method designed to be used in variable frequency drives to control the torque of a three phase AC motor, from which the speed of it can eventually be manipulated. The main components in a conventional DTC include a decoupled control of the motor torque and motor flux magnitude. The general working principle of a DTC is to tune the inverter to the corresponding instantaneous error estimated in torque and stator flux magnitude of the motor. From it, the inverter is switched to the appropriate voltage vectors basing on a switching table to be fed into the induction motor. To improve the overall performance of the system and to achieve a constant switching frequency, the hysteresis comparator in a DTC-SVM is replaced by PI torque and flux comparators. The switching mechanism is also replaced by an SVM, as shown in Figure 2.

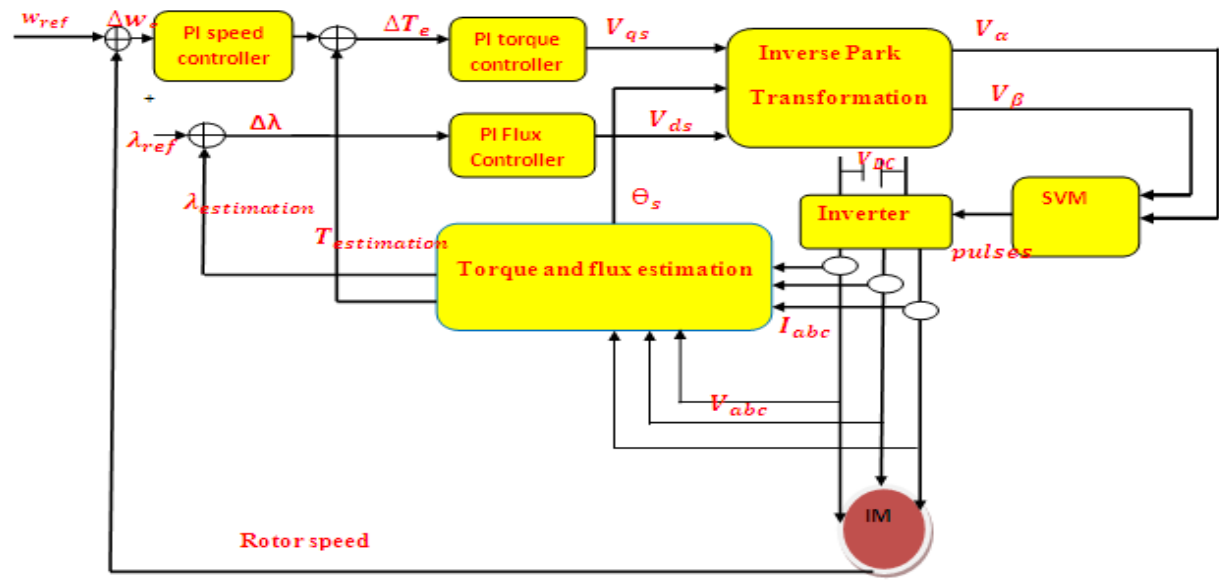

Figure 2. The block diagram of DTC-SVM

\section{CLOSED LOOP FLUX ESTIMATION}

The calculations in the DTC-SVM algorithm are based on averaged values while the switching signals for the inverter are generated by the space vector modulator. There are several issues with this arrangement that affect the overall performance of the system especially during low motor speed. Among others is the open loop integration of stator flux estimation which can cause DC drifts and saturations. The estimated stator flux values can greatly affect the overall performance of a DTC. This motivated us to come up with a method to overcome this problem. A closed loop integration algorithm for stator flux estimation is proposed. The calculations in the algorithm are based on stator current and voltage model in a low pass filter. The general block diagram is as shown in Figure 3.

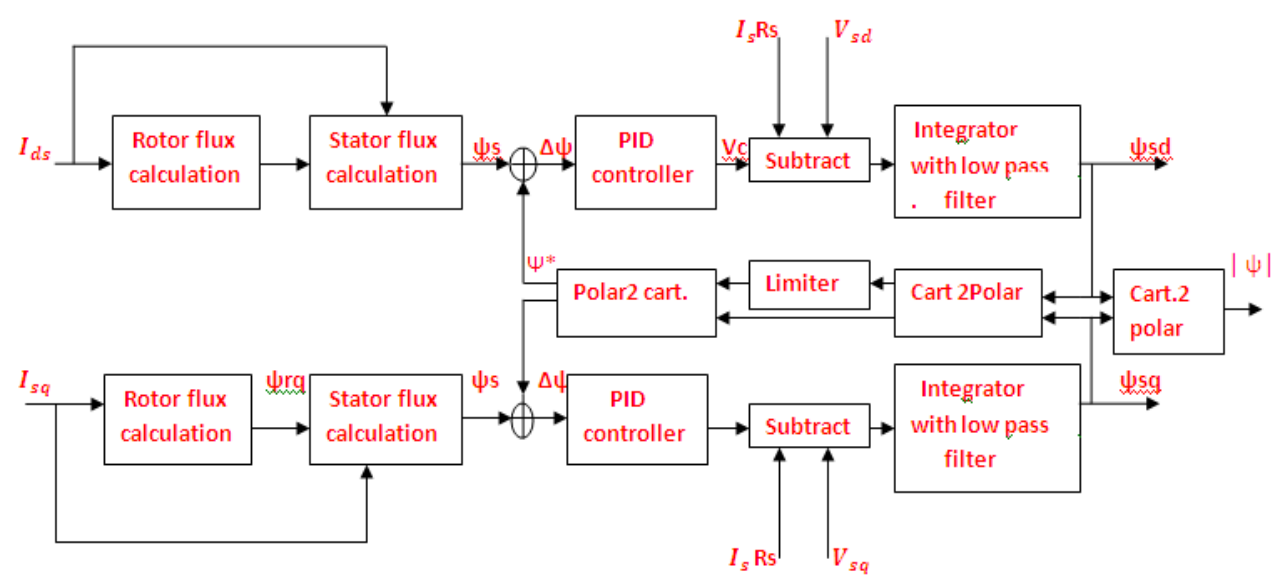

Figure 3. The block diagram of the stator flux estimation scheme 
The transfer function is as shown in equation (7).

$$
\frac{\psi_{s d}(s)}{\Delta \psi_{s}}=-\frac{\left(K_{p} s+k_{i}\right)}{s} * \frac{T_{s} * w_{c}}{(s+20)}
$$

Figure 4 shows the closed loop stator flux estimation in direct axis as derived from equation (7) in the form of a block diagram.

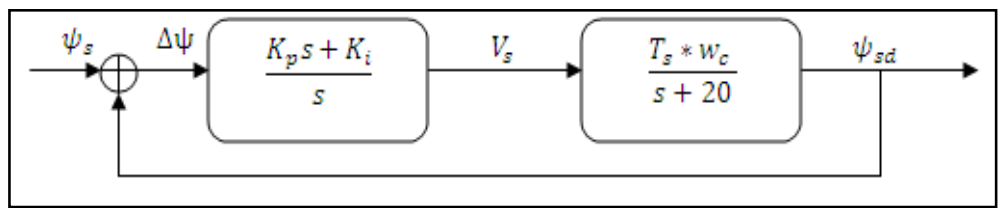

Figure 4. The block diagram of the closed loop stator flux estimation

\section{FUZZY LOGIC CONTROLLER}

A fuzzy logic control scheme (FL) is adapted into the proposed method. The estimated torque values are compared to their references and the errors obtained are fed as inputs into the FL. These errors are normalized and the values are within the range of -1 to +1 . The FL minimizes the torque errors and obtains property voltages in quadrature reference frame (Vqs) with constant switching frequencies. The proposed FL is as illustrated in Figure 5. The PI torque and flux controller in the conventional DTC is replaced by two fuzzy logic controllers. The estimated value of stator flux is compared to the actual stator flux value. The calculated error is then fed into the fuzzy logic controller. This minimizes the total harmonic distortion of the stator current.

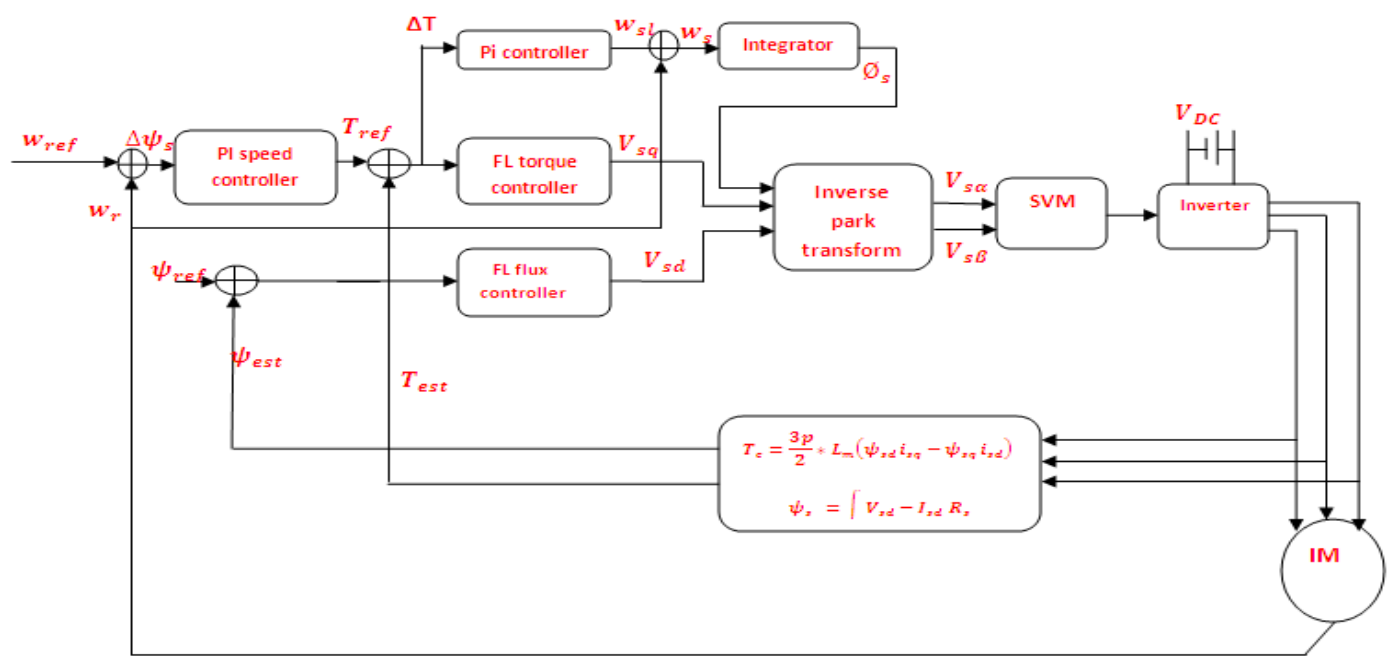

Figure 5. The block diagram of the fuzzy logic control in a DTC

Figure 6 shows the closed loop block diagram of stator flux reference value and the stator flux estimation magnitude.

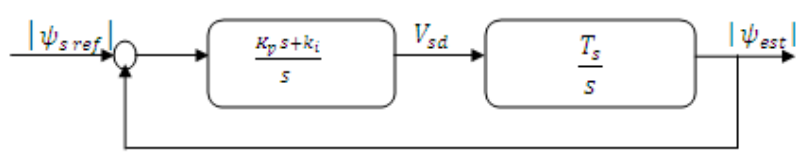

Figure 6. The block diagram of the flux control loop 


\section{SIMULATION RESULS}

Experimental simulations were carried out in MATLAB/SIMULINK in order to verify the proposed scheme. The stator flux and torque estimation loop for the drive are also designed and included in the simulations. The proposed torque and flux fuzzy regulators are developed using the fuzzy Toolbox. Table 1 shows the parameters setting of the induction motor. The efficiency and overall performance of the enhanced method with fuzzy logic feature (as shown in Figure 5) is benchmarked with that of a conventional SVMDTC.

A very low speed operating condition of $50 \mathrm{rad} / \mathrm{sec}$ under full-load torque $(14.5 \mathrm{Nm})$ is set for performance benchmarking. Figure 7 shows the steady state response comparison of the modified SVM-DTC with a conventional SVM-DTC under such operating condition. It can be observed that the modified SVMDTC yielded much smoother steady state performance graphs, especially in terms of torque and rotor speed. The modified scheme achieved a steady state of rotor speed in a minimal of 0.2 second. The rotor speed of the conventional SVM-DTC, on the other hand, overshot to 15rad/sec with significant ripples and reached steady state only after 2.2 seconds. With the enhancing features in the proposed method, the overshoot in torque is significantly reduced from $27 \mathrm{Nm}$ to $14 \mathrm{Nm}$. Undershoot condition is also eliminated with the implementation of the proposed scheme. The ripples of the torque is reduced $70 \%$ from $1 \mathrm{Nm}$ to $0.3 \mathrm{Nm}$. The starting current is also successfully reduced from 14A to $10 \mathrm{~A}$ with no significant distortion. The enhanced scheme yielded ripple-free stator flux at steady state. The torque error between estimated torque and its reference is at mere $0.2 \mathrm{Nm}$ as a constant switching frequency is achieved using the modified method. In comparison, the torque error in the conventional SVM-DTC changes from $0.2 \mathrm{Nm}$ to $-2 \mathrm{Nm}$ due to variable switching frequency and low control system performance.

Table1. The parameters setting of the induction motor

\begin{tabular}{|llc|}
\hline 3 -phase & $2.2 \mathrm{Kw}$ & $R_{s}=3.2 \Omega$ \\
$50 \mathrm{~Hz}$ & 4 -poles & $R_{r}=2.1 \Omega$ \\
$400 \mathrm{~V}$ & $5 \mathrm{~A}$ & $L_{s}=0.24 \mathrm{H}$ \\
$N_{r}=1450 \mathrm{rpm}$ & $L_{m=0.2}$ & $L_{r}=0.24 \mathrm{H}$ \\
\hline
\end{tabular}

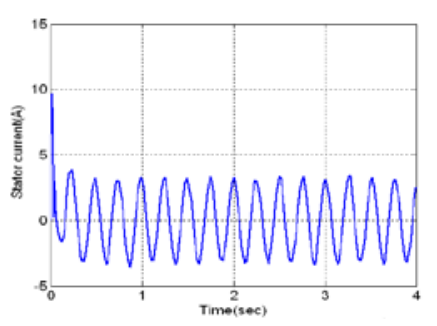

a. Stator current

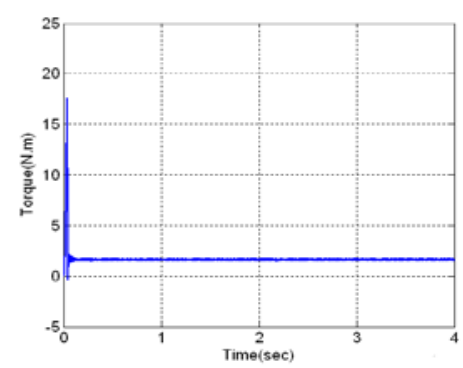

b. Electromagnetic torque

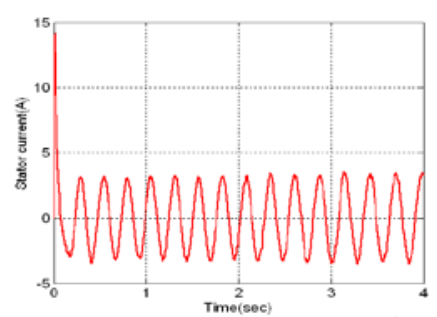

f. Stator current

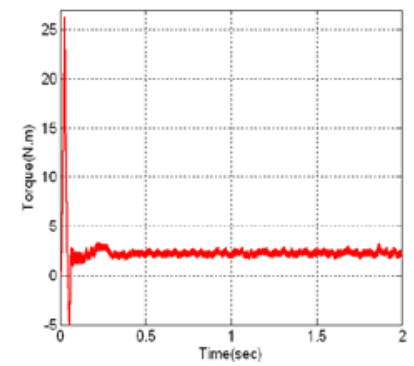

g. Electromagnetic torque

Figure 7. (a)-(j) Results comparison of the proposed method in blue and a conventional SVM-DTC in red 


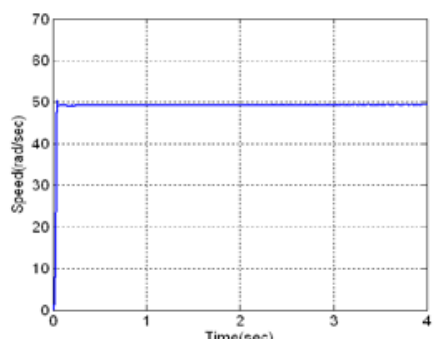

c. Rotor speed

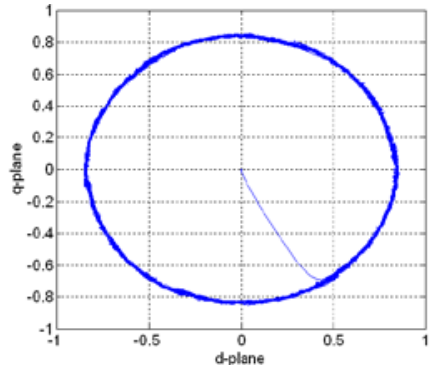

d. Stator flux

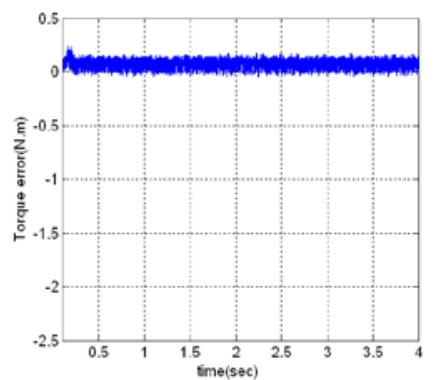

e. Torque error

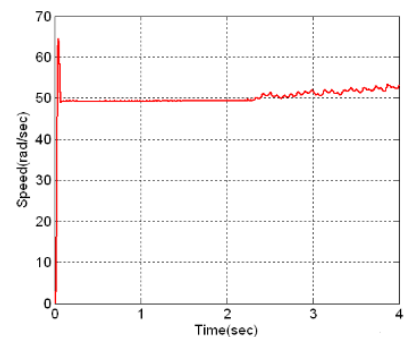

h. Rotor speed

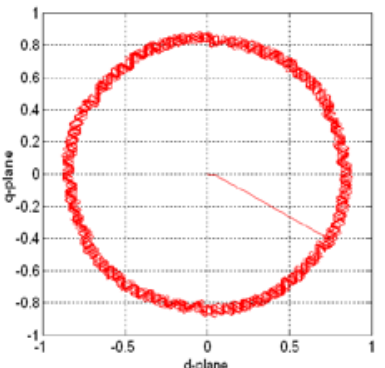

i. Stator flux

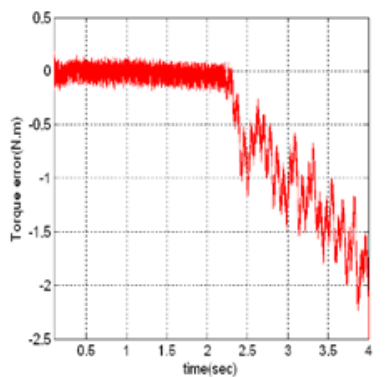

j. Torque error

Figure 7. (a)-(j) Results comparison of the proposed method in blue and a conventional SVM-DTC in red

\section{CONCLUSION}

In this paper, a modified DTC-SVM with the enhancements of fuzzy logic control and closed loop stator flux estimation is proposed for asynchronous motor drives. Instead of a conventional PI controller, a fuzzy logic controller is used for torque controlling with the aim to minimize the error between estimated torque value and its reference. On the flux control, the implimented fuzzy logic algorithm successfully minimized the total harmonic distortion of the stator current by reducing the error between the estimated stator flux and the stator flux reference.

In the proposed modification also includes a closed loop stator flux estimation. The purpose of implementing a closed loop flux estimation is to overcome DC drifts and saturation problems. Simulations and hardware experiments were conducted. The results indicate that the modified DTC-SVM is able to reduce the ripples in generated torque and flux. This enhanced DTC-SVM also successfully minimized the distortion in stator current with fast response of rotor speed change. It can thus be concluded that the modified DTC-SVM enhanced with closed loop stator flux estimation and fuzzy logic control performs well in general-purpose asynchronous motor drives.

\section{ACKNOWLEDGEMENT}

The authors would like to thank the Malaysia Ministry of Higher Education for the support of this research under Fundamental Research Grant (FRGS). 


\section{REFERENCES}

[1] I. Takahashi and T. Noguchi, "A new quick-response and high efficiency control strategy of an induction machine," IEEE Trans. Ind. Applicat, vol. 22, pp. 820-827.Oct. 1986.

[2] $\mathrm{H}$ Nasution. Development of fuzzy logic control for vehicle air conditioning system. TELKOMNIKA (Telecommunication Computing Electronics and Control). 2008; 6(2): 73-82.

[3] T.G. Habetler, D.M. Divan, “Control strategies for direct torque control using discrete pulse modulation,” IEEE Trans. Ind. Appl, vol.27, pp.893-901, 1991.

[4] K PitchaiVijaya, KK Mahapatra. Adaptive-fuzzy controller based shunt active filter for power line conditioners. TELKOMNIKA (Telecommunication, Computing, Electronics and Control). 2011; 9(2): 203-210.

[5] N. Rumzi Nik Idris, A. Mohamed Yatim, "Direct Torque Control of Induction Machines With Constant Switching Frequency and Reduced Torque Ripple,” IEEE Trans on Industrial Electronics, Vol. 51, No. 4, pp. 758 -767, August. 2004.

[6] Brahim Metidji, Farid Tazrart, Ahmed Azib, Nabil Taib, Toufik Rekioua “ A New Fuzzy Direct Torque Control Strategy for Induction Machine Based on Indirect Matrix Converter,” International Journal of Research and Reviews in Computing Engineering, vol. 1, no.1,pp.18-22, March 2011.

[7] N Baatar, S Kim. A Thermoelectric Generator Replacing Radiator for Internal Combustion Engine Vehicles. TELKOMNIKA (Telecommunication, Computing, Electronics and Control). 2011; 9(3): 523-530.

[8] A. Lokriti, Y. Zidani, and S. Doubabi, "Fuzzy logic control contribution to the direct torque and flux control of an induction machine,” IEEE International Conference on multimedia Computing and Systems,pp.1-6,July 2011.

[9] S.M. Gadoue, D. Giaouris, and J.W. Finch, "Modified Direct Torque Control Method for Induction Motor Drives Based on Amplitude and Angle Control of Stator Flux,” Electric Power Systems Research,pp210-219,July 2008

[10] Yen-Shin Lai, and Juo-Chiun Lin, "New Hybrid Fuzzy Controller for Direct Torque Control Induction Motor Drives,” IEEE Transactions on Power Electronics,vol.15, no.5,pp.1211-1215,September 2003.

[11] Luis Romeral, Antoni Arias, Emiliano Aldabas, and Marcel. G. Jayne,"Novel Direct Torque Control (DTC) Scheme With Fuzzy Adaptive Torque-Ripple Reduction,” IEEE Transactions on Industrial Electronics, vol. 50, no. 3,pp.487-492, June, 2003.

[12] Jun Zhang, and M. F. Rahman "Analysis and Design of a Novel Direct Flux Control Scheme for Induction Machine,’IEEE International Conference on Electric Machines and Drives, pp.426-430,May 2005.

[13] A. Abbou, Y. Sayouti, H. Mahmoudi,and M. Akherraz, "Fuzzy inference system based direct torque control,” IEEE in Control and Automation,pp.1121-1126,August 2010.

[14] Jian Wang, Hong-hua Wang, Xiao-ling Yuan,and Tian-hang Lu, “Novel Intelligent Direct Torque Control for Permanent Magnet Synchronous Motor Drive ," IEEE on Fuzzy System and Knowledge Discovery,pp.226230,November 2008.

[15] Zheng Li .and Yi Ruan. “A Novel Control Method Based on Wavelet Neural Networks for Direct Torque Control in Induction Motor Drives,” International conference on Electrical machines and system, pp. 3967-3972, 2009. 